\title{
Will developing countries benefit from their participation in genetics research?
}

\section{Paul Ndebele $^{1,}$ Rosemary Musesengwa ${ }^{2}$ \\ 1. Centre for Bioethics in Eastern and Southern Africa, College of Medicine, Malawi \\ 2. Medical Research Council of Zimbabwe, Zimbabwe}

Corresponding author: Paul Ndebele, Centre for Bioethics in Eastern and Southern Africa (CEBESA), Department of Community Health, College of Medicine, Private Bag 360, Chichiri, Blantyre 3, Malawi

Phone: +2651871911 ext 310, Email: pndebele@medcol.mw

\begin{abstract}
There is an increase in the amount of genetics research being conducted in both developed and limited resource countries. Most of this research is sponsored by developed countries. There are concerns in limited resource countries on how the benefits from this research are currently being shared or will be shared in the future. There is need for caution, to ensure that populations from limited resource countries are not exploited by being used as subjects in genetics research which is meant to benefit populations from developed countries. This paper addresses the issue of fairness in benefits sharing and argues for justice in the sharing of both burdens and benefits of genetics research. The paper responds to some of the issues and arguments in recent literature on the meaning and limits of the concept of benefit sharing in human genetics research.
\end{abstract}

\section{Introduction}

While the greater majority of genetics research studies are currently being conducted in and by developed countries, limited resource countries are currently also witnessing an increase in the amount of genetics research being conducted on their populations. This increase brings with it social, legal and ethical implications, and among them are the issues surrounding how the benefits of this research are shared. Most of the genetics research being conducted today focuses on diseases of affluence whilst ignoring the diseases of poverty. ${ }^{1}$ There are currently some debates going on the avoidance of exploitation of weaker parties in international research and we argue that international research will only continue to flourish based on cooperation, collaboration and respect of limited resource country views and values by developed country counterparts. ${ }^{2}$ Limited resource countries continue to play an important role in research as they provide a fertile ground for clinical trials due to various reasons including the serious burden of disease and ready availability of willing volunteers.

\section{Defining benefit sharing}

We outrightly acknowledge that this paper only deals with the issue of benefits sharing from the point of view of health benefits. We recognize that in human genetics research, there are other benefits such as profits, jobs and others. We also note that there are other important issues that need attention such as ownership rights and other legal issues. While we acknowledge their importance, we feel that the other issues are better off being addressed by others who are competent to unpack the complications as well as the contradictions they bring about. Shroeder defines benefit sharing as the action of giving a portion of advantages or profits derived from the use of human genetic resources to those persons who would have provided those resources so as to achieve justice. ${ }^{3}$ Shroeder emphasises on the provision of benefits to those who lack reasonable access to products and services resulting from the research without providing undue inducements. This definition is adopted in this paper as it is very relevant to poor countries and communities which are easily tempted by the various inducements that may be offered in exchange for volunteering.

\section{Status of genetics research}

Much of the genetics research conducted in limited resource countries is sponsored by agencies and governments from developed countries and most of the studies are meant to address problems of people from these countries who can also afford the new genetic technologies. ${ }^{4} \quad$ While limited resource countries are not directly involved in directing the research agenda in genetics research, they are acting as a rich source of biological materials for genetics research. The current scenario prevails because developing countries face limitations in terms of the financial and technological resources necessary to undertake such research.

In order to illustrate this unfair situation, the term "postal research" has since been coined to refer to studies where developing countries courier biological materials to the west. The term "parachute research" has been coined to refer to western researchers who travel to developing countries to collect biological samples and take them to their countries for analysis and the exploitation of the research findings, never to be seen again in the developing country sites where they would have collected their specimens. Several other terms have been developed to reflect this situation. Other authors have even gone as far as describing a "biotechnology gold rush" in which the territory is the human body. ${ }^{5}$

While the genetics research stakeholders in the developed countries appear to be more organized in terms of disease specific research foundations, disease associated advocacy groups and other structures which represent and serve the interests of the various stakeholders in research, limited resource countries do not have such pronounced structures. Where such structures are in existence, they are still in their formative stages or they are sub-units of mother bodies in rich countries, and hence they are not very influential in such decisions as the sharing of benefits. The major players when it comes to benefit sharing in developing regions are; the countries, institutions, researchers, research subjects and research ethics committees, which are a recent feature in most limited resource countries. Limited resource country governments and institutions have little or no budgets set aside for genetics research as they have to battle with the serious levels of poverty.

\section{Levels of benefit sharing}

The issue of benefits sharing, can be looked at from two levels 
; the micro level where one can focus directly on the research subject who directly participates in the research, as well as at the macro level, where one may focus on communities or countries that participate in research as well as the global situation (limited resource and developed countries). At the micro level, the issue of benefit sharing can be looked at in terms of the principle of "compensation". The principle of compensation can be viewed from two different angles. Compensation may take the form of a direct payment for participation. Compensation may also take the form of participation in the eventual economic and other benefits. ${ }^{6}$ Compensation for participation is straight forward and easier to address as each subject is compensated for the time spent, the pain and other inconveniences. The payment is made on the subject's cooperation in a scientific programme. It may also be made on the sale of the blood sample or other bodily tissues. The UNESCO Sub-committee on Population Genetics, strongly emphasises that undue inducement through compensation is not and should never be encouraged. $^{7}$

As regards participation in the eventual benefits, the Declaration of Helsinki offers clear guidance especially for research conducted in the developing countries. The year 2000 version of the Declaration of Helsinki states categorically that at the end of any research study, every subject entered in the project should be assured of the best proven prophylactic, diagnostic and therapeutic methods identified by that study. The World Medical Assembly emphasizes that medical research is only justified if there is a reasonable likelihood that the populations in which the research is carried out stands to benefit from the results of the research. ${ }^{8}$

One issue that arises when considering whether it is appropriate or not to conduct a specific study within a developing country is whether the intervention being studied is likely to be affordable to that country or not. Participants in the research may have a condition requiring ongoing treatment. In such cases there is an obligation to continue to provide an intervention that has been shown to be effective to all participants? Whose responsibility should it be? Serious criticisms have thus been levelled against the Declaration of Helsinki for emphasizing that at the end of a study, every subject entered into the study should be assured of access to the best proven prophylactic, diagnostic and therapeutic methods identified by that research. The Nuffield Council on Bioethics notes that this may also be difficult to implement especially in relation to ongoing treatment for chronic diseases. ${ }^{\text {? }}$

\section{The role of the Ethics Committees in benefits sharing}

The National Bioethics Advisory Commission (NBAC) in its report even goes further to recommend that researchers should before initiation of a research study, endeavour to secure access for all participants to effective treatment after the trial and that the lack of any such arrangements should be justified to a research ethics committee (REC). ${ }^{10}$ The report also recommends that researchers should indicate in their proposals how they intend to make the intervention available to participants after the trial if the intervention is proven successful. It even goes further to recommend that researchers should justify to the REC why the research should be carried out in that country. It is however important to note that the availability of an intervention after trial depends on several factors including cost of providing the intervention, supervising its administration, the necessary infrastructure required and others.

As a further way of ensuring that developing countries are not used as sites for research that is not of relevance to them, the Council for International Organisations of the Medical Sciences Guidelines specifically state that all research that is conducted in developing countries and sponsored by developed countries, should be of relevance to the developing countries. ${ }^{11}$ The relevance of the study to the country is a sure way of ensuring that countries stand to benefit once their citizens participate as subjects of genetics research. It is however important to note that while relevance and benefit sharing are very important, it is very difficult to formulate guidelines which satisfactorily address the issue of benefit sharing.

\section{Benefits from pharmacogenomics}

Many hope that pharmacogenomics will change the face of medicine by reducing the number of people who die from adverse drug reactions each year and also by enabling identification of the most efficacious drugs for individuals. Pharmacogenomics is the study of how an individual's genetic inheritance affects the body's response to drugs. The term comes from the words pharmacology and genomics and is thus the intersection of pharmaceuticals and genetics. According to its proponents, pharmacogenomics holds the promise that drugs might one day be tailor-made for individuals and adapted to each person's own genetic makeup, environment, diet, age, lifestyle, and state of health. Understanding an individual's genetic make-up is thought to be the key to creating personalized drugs with greater efficacy and safety. ${ }^{12}$

Whilst a lot continues to be mentioned in glorifying pharmacogenomics, the question that however needs to be asked is whether developing countries will benefit from pharmacogenomics in the above ways. Who will be the target of drug production by pharmaceutical companies? Who will be left behind in new drug development? Will developing countries health problems be addressed through pharmacogenomics? Drug companies always think about maximizing their profits and are usually interested in catering for those diseases from which they can reap the most profits.

At the global level, the Human Genome Organisation Ethics Committee has issued some very important recommendations regarding benefit sharing, aimed at ensuring that developing countries, participate in sharing the benefits from genetics research. ${ }^{13}$ Some of the recommendations with a bearing on benefit sharing include the following :

\section{- All humanity (including developed countries) should share} in and have access to the benefits of genetics research.

- Benefits should not be limited only to those individuals who participated in such research.

- There should be prior discussion with groups or communities on the issue of benefit sharing in this case RECs and community representatives.

- Even in the absence of profits, immediate health benefits as determined by the community needs should be provided. 
- At a minimum all research participants should receive information about general research outcomes and a general indication of appreciation.

- Profit making entities should dedicate a percentage of their annual net profits to health care infrastructure and/or humanitarian efforts.

The above recommendations are based on the simple fact that the human genome is the common heritage of humanity since all mankind share in essence the same gene. The committee notes that currently there is a great inequality between rich and poor nations in the direction and priorities of research and in the distribution and access to the benefits thereof, hence the recommendation that all countries should share in the benefits of genetics research. The moral arguments that are highlighted by Kadri Simm of duty not to exploit the vulnerable and duty to alleviate suffering, are very strong when one considers the history of exploitation between the developed and limited resource countries. ${ }^{2}$ The arguments also hold when one considers the role the limited resource countries continue to play in further advancing the development of developed countries through the provision of cheap research specimens. The argument about the special moral obligations of medical enterprises is also very important considering that health problems are not contained by national or geographic boundaries. Instead of leaving the private enterprises to play their role in medical research unchecked, we argue for the increased involvement of the United Nations in topical areas such as genomics, cloning and others so as to deal with the selfish arguments as well as the contradictions that drive parties into different camps.

Research Ethics Committees being the gatekeepers when it comes to health research, can play an important role of ensuring that the communities and individuals are not exploited in research. More often, it is very difficult for a community to voice its concerns due to various reasons including lack of appropriate structures for communication. The ethics committees are made up of various members, knowledgeable in research and other issues and can therefore serve as the voice of the voiceless communities and individuals in developing countries. We completely disagree with others who suggest that benefit sharing is conceptually problematic. We argue that we need not only focus on profits but on ways of ensuring that poor communities benefit after participating in genetic research in one way or the other. While we acknowledge the concept of genetic solidarity as a moral ground for benefit sharing, ${ }^{5}$ we argue that developing countries and institutions need to come to the negotiating table with pride since they have a very useful resource in research - human beings that are willing to participate in research. We note that where money is involved, it is easy to forget about solidarity in favour of profits. Others may want to look at arguments in support of benefit sharing as encouraging bribery for people to participate in research. ${ }^{5} \mathrm{We}$ maintain that benefit sharing ensures that the disadvantaged at least benefit in some way from an activity in which they have participated in.

\section{Conclusion}

In this paper we take the view that at both the micro level and the macro level, compensation for participation in any commercially exploitable genetic research is the fairest thing to do and that this compensation should not only be in monetary terms but can also take the form of health benefits, technology transfer, scientific, technical and medical training, installation and ongoing maintenance of infrastructure such as laboratories, clinics, libraries and other facilities. We also argue that Research Ethics Committees in developing countries should be strengthened so that they can make informed decisions on sharing the benefits of research and other important issues. We put forward that RECs should negotiate on behalf of their communities by ensuring that on granting permission to any genetics research projects that are commercially exploitable, they insist that this should be made clear at the outset to the participants and that this must be part of the recruitment and informed consent process as well as the contracts between scientists from the developed countries and their counterparts from the developing countries. We also put forward that RECs in developing countries should play the extra role of ensuring that the researchers and their institutions negotiate these issues before research is performed on behalf of the research participants and their own countries.

Developing country research participants should be given a voice in decisions affecting access and benefits from commercialized products. This can only be achieved if they are educated on genetics research and what the new research findings may mean to them. Unless action is taken, it is likely that benefits from genetic research will only accrue to the rich nations and rich people - and this is but unfair. Sharing the benefits of genetics research is one sure way of addressing the inequalities between the rich and poor nations.

\section{References}

1. Schuklenk U and A. Kleinsmidt. 2006. North-South benefit sharing arrangements in bioprospecting and genetic research: A critical ethical and legal analysis. Developing World Bioethics. 6 (3), 122-134

2. Simm K. 2005. Benefit-sharing: an inquiry regarding the meaning and limits of the concept in human genetic research. Genomics Society and Policy, Vol.1, No.2, 29-40

3. Shroeder D. 2007. Benefit sharing: Its time for a definition. Journal of Medical Ethics.: 33: 205-209

4. Global Forum for Health Research. 2002. The 10/90 Report on health research. 2001-2002. AGL FM Productions. Switzerland.

5. Dickenson D. 2004. Consent, commodification and benefit sharing in genetic research. Developing World Bioethics. Vol 4. No2: 109-124.

6. Knoppers BM, Chadwick R. The Human Genome Project: Under International microscope. Science; 1994;265:2035

7. UNESCO. 1995. Sub-committee on population genetics of the UNESCO. International Bioethics Committee. Draft Report on Bioethics and Human Genetics Research. 1995.

8. World Medical Assembly 2000. Declaration of Helsinki - Ethical Principles for medical Research involving human subjects, Adopted by the 52nd WMA General Assembly, Edinburgh, Scotland October 2000

9. Nuffield Council on Bioethics. 2002. The ethics of research related to healthcare in developing Countries. Latimer Trend Group. UK

10. National Bioethics Advisory Commission (US). 2001. Ethical and policy issues in international research: Clinical trials in developing Countries

11. Council of International Organisations of Medical Sciences. 1993. International Ethical Guidelines for Biomedical Research involving human subjects.

12. .Griffin P, in "The challenges and impact of human genome research for minority communities: Proceedings from a conference presented by Zeta Phi Beta Sorority, Inc. National Educational Foundation. 2000. Philadelphia. Available at http://www.ornl.gov.hgmis/publicat/ zetaphibeta/epps.html. (Accessed 23/3/2003)

13. Human Genome Organisation Ethics committee 2000. Statement on benefit sharing. Available at :http://www.gene.ucla.ac.uk/hugo/ benefit.html (Accessed 24/3/2003 